\section{My long journey}

I swoop and turn, air moves through my hair, reminding me of my Mom's fingers running over my head at bedtime to help me sleep. Only I feel the helmet holdin' my head tight, like it's keeping my hair from flyin' right off my head. Gosh, I like riding my bike. It makes me think of what it'd be like to be a bird. I can fly.

I can fly. Really. 'Cause now I am out of the bright sun and in some kind of an inside place I don't know where. Alls I know is that I am flying above myself. It's kinda weird, you know, lookin' down on yourself. I know I can't really do this so I think I'm havin' some weird dream or somethin'.

I don't get it, like one second I'm riding my bike feeling so good I'm almost flying and now I'm actually flying above myself and looking down at me. Like I said, weird, right? You figure it out.

And here's the other thing. There's a bunch of people around me an' I'm lying on some kind of a strange bed with wheels on it 'stead of legs. Who the heck has wheels on their bed? But, it might be kinda fun to try at home. So like you wouldn't have to get dressed or even get out of bed for breakfast, you could just wheel yourself into the kitchen and eat your Cheerios. Well, if you like to eat Cheerios, you know?

Anyways, like I said, there's a bunch of people around me and no one looks like they're havin' fun. They're all nerved up or something. My Dad was always telling my Mom who borned me not to get all nerved up. He doesn't tell my new Mom not to get all nerved up. Which is good 6 that he doesn't have to say that. And anyways, when I'm with my Mom who borned me, she doesn't get that way anymore. And if you ask me, it's because my Dad isn't there telling her not to. Another thing that's kinda strange, if you think about it.

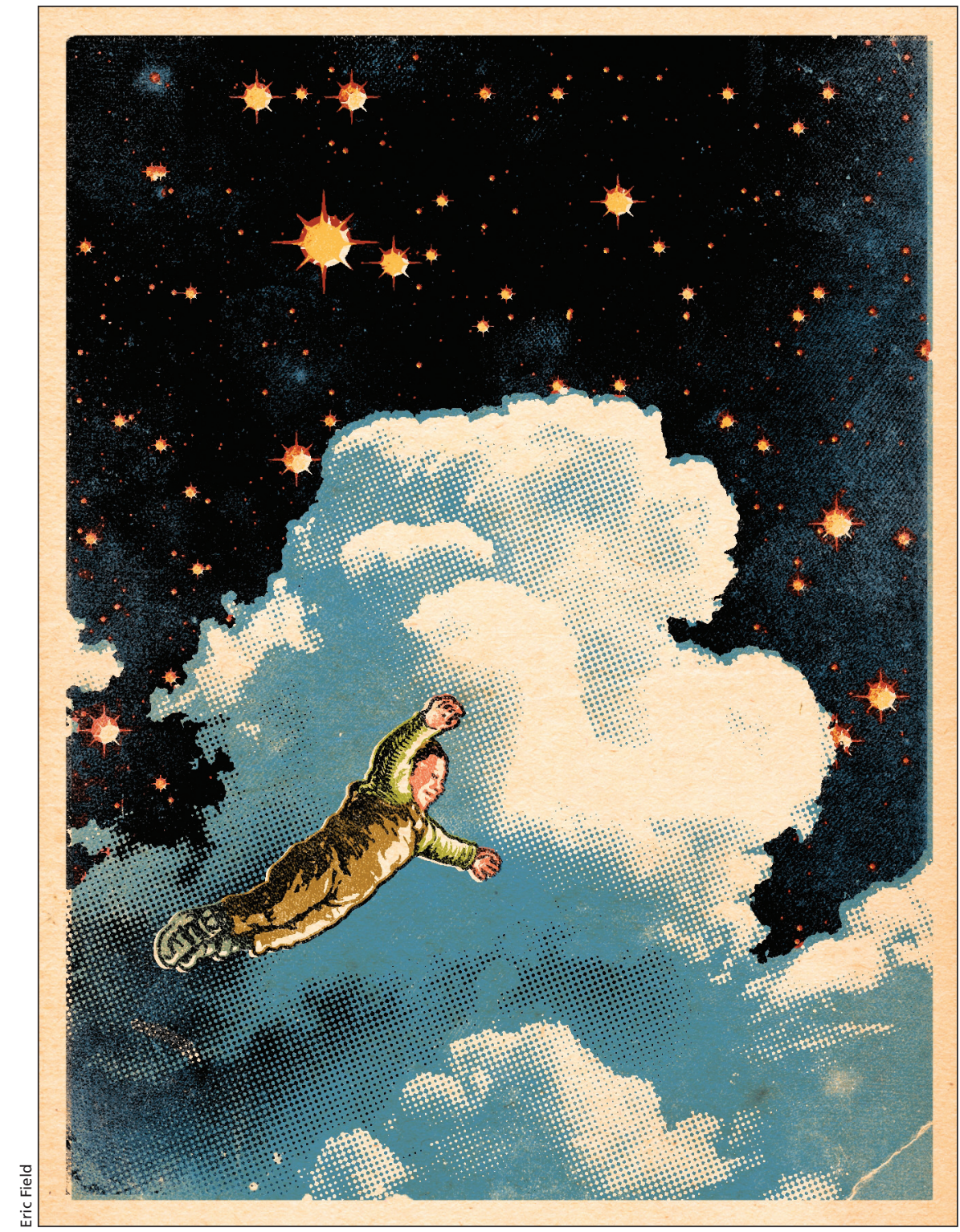

And then I hear someone say this, "Thoracotomy tray now, please." Look, I don't know what that means either so don't even ask, okay? But here's the next weird thing that happens. I can feel someone on the other side of the curtain get a sudden knot in her tummy and I feel her knees give out a bit, like she's wobbly. And I know somehow that she's thinking about her kids at home. So, I am wonderin' if "thoracotomy" is like a real bad swear word you should never use in front of kids. And if it is, I'm sorry for usin' it.

I'm back. I went away for a couple of minutes. I felt something squeezing around my heart and heard a real slow beep-beep-beep and then it got faster and I wasn't flying anymore. But now I'm back looking down at me and who 


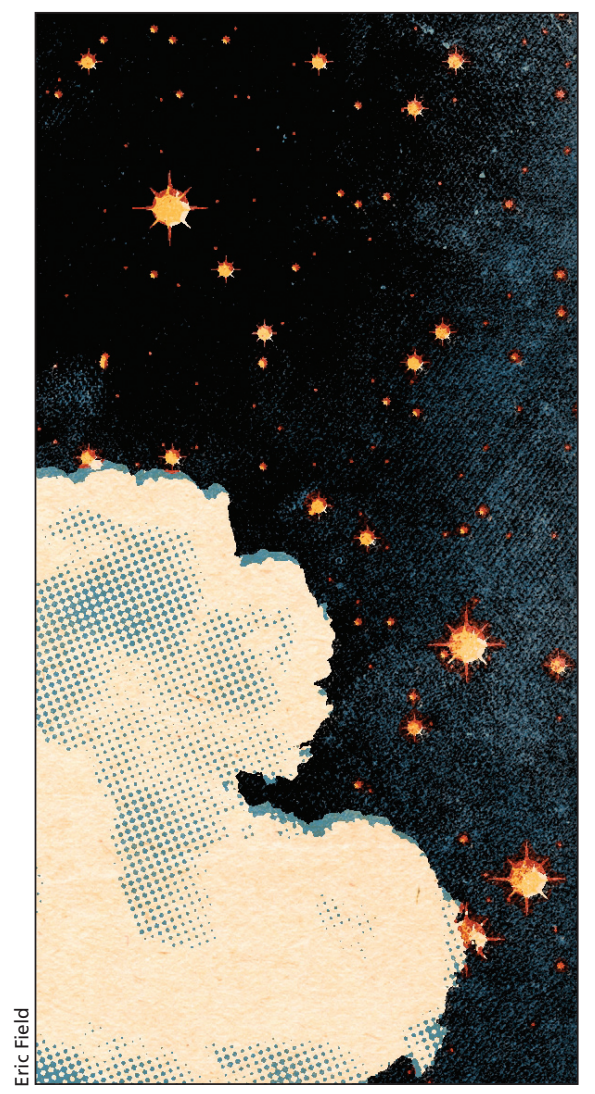

do you think I see? Both my Moms and my Dad!

And both Moms are crying and my Dad looks like he's gonna get sick and he's holding onto one of the ladies in the blue pajamas. Who the heck has a job where you wear blue pajamas to work? That's so dumb. Lame, my friend Connor would say. And my parents, all three of them, are talking to me. They're saying things like: "I love you, Spence."(which, in case you didn't figure it out, is short for Spencer) knows I would never forget our camping trip so I don't know why he's saying that to me.

But now that I think about it, I couldn't answer even if I wanted to 'cause there's a thick tube coming out of my mouth. C'mon, how could I talk with that thing in there? And did I say there are little tubes coming out of my arms? And promise you won't tell anyone? Promise? There's one even coming out of my uhm, thingy, you know, my penis.

And then the next super weird thing happens. Okay, I know I should find a different word than weird, but I'm only seven years old and when I say weird it's because that's what it is.

So the super weird thing is I'm starting to hear music. And letters are popping into my head: e, b and a. No, that's not right. Should be capitals: E, B and A. Don't know why I know this. Don't know 'zackly what the letters mean 'cept it's about the music. And where the music is coming from is I think from everybody here in this room cut off from the others by curtains.

Look, it's a dream and I don't have to 'splain to you what doesn't really make sense to me. So, it's like this. The people who are not my parents are playing instruments, like guitar, bass, banjo, drums and some weird one that I think is called an autoharp. But they don't actually play them, it's just flowing out of them. The music, I mean, is just streaming out of them. Instead of tears, there's music and that's the best way I can 'splain it to you. And so the singing is left to my parents, my Moms

\section{"Instead of tears, there's music and that's the best way I can 'splain it to you."}

and "Hang in their buddy." and "Don't forget our camping trip in 2 weeks."

And in this dream that I'm having, I'm not answering. I want to reach down and punch me on the arm for being so rude. I mean, when parents talk, you should answer. Unless you're watching TV and you can't because you're too busy concentrating. Which happens to me a lot. But anyways, Dad share one voice and my Dad is the other one.

And why it's so strange is that my Dad can only sing in the shower and my Moms can't sing at all, either one of them. But my Dad is really crying now and maybe that's kinda like a shower, so I'm guessing that's where the beautiful voices come from.

Look, this is the last thing I'm gonna tell you 'cause I'm gettin' real cold and I'm so tired. That and it feels like my dream is pullin' me away from here. Like, I'm floatin' to a warm place. Wow! It's gonna be bright there, too. It seems like I won't have to watch my parents cry anymore. And anyways, just so you know, this dreamy place I'm going? It isn't so bad. I know this; I feel it already.

So there, can you hear it? The song they're singing? Shhh, just listen. Listen to the song:

\section{Your Long Journey}

God's given us years of happiness here Now we must part

And as the angels come and call for you

The pains of grief tug at my heart Oh my darling

My darling

My heart breaks as you take your long journey

Oh the days will be empty

The nights so long without you my love And when God calls for you I'm left alone

But we will meet in heaven above Oh my darling

My darling

My heart breaks as you take your long journey

Fond memories I'll keep of happy ways That on earth we trod

And when I come we will walk hand in hand

As one in Heaven in the family of God Oh my darling

My darling

My heart breaks as you take your long journey*

\section{Brian Deady MD}

Emergency Department

Royal Columbian Hospital

New Westminster, BC

The author wishes to acknowledge the version of "Your Long Journey" by Robert Plant and Alison Krauss on their album, Raising Sand as the musical inspiration for this story.

\footnotetext{
* Rosa Lee Watson, AD Watson. Your long journey [song lyric]. Hillgreen Music (BMI); 1986.
} Reprinted by permission of the publisher. 